1

2

3

4 Yan Yan $^{1,2}$, Chao Li ${ }^{1,3}$, Zhen Liu ${ }^{4}$, Jun-Jie Zhuang ${ }^{1}$, Jia-Rui Kong ${ }^{1}$, Zhen-Kun Yang ${ }^{1}$, $5 \quad$ Jie $\mathrm{Yu}^{4}$, Mohammad Shah Alam ${ }^{1}$, Cheng-Cheng Ruan ${ }^{1}$, Heng-Mu Zhang ${ }^{2 *}$, Jian-Hong 6

7

$8{ }^{1}$ Institute of Crop Science, Zhejiang Key Laboratory of Crop Germplasm, Zhejiang

9 University, Hangzhou 310058, China

\section{A new demethylase gene OsDML4 involved in high temperature induced floury} endosperm formation in rice (Oryza sativa L.)

${ }^{2}$ Institute of Virology and Biotechnology, Zhejiang Academy of Agricultural Sciences, Hangzhou 310021, China

${ }^{3}$ Shandong (Linyi) Institute of Modern Agriculture, Zhejiang University, Shandong 276034, China

${ }^{4}$ Hainan Institute, Zhejiang University, Sanya, Hainan 572000, China

${ }^{*}$ Corresponding author: Jian-Hong $\mathrm{Xu}$

Address: Institute of Crop Science, Zhejiang University, 866 Yuhangtang Road, Hangzhou, Zhejiang 310058 China

E-mail: jhxu@zju.edu.cn

Telephone: 86-571-88982406

Heng-Mu Zhang

Address: Institute of Virology and Biotechnology, Zhejiang Academy of Agricultural Sciences, 198 Shiqiao Road, Hangzhou, Zhejiang 310021, China

E-mail: zhhengmu@tsinghua.org.cn

Telephone: 86-571-86404258 
27 Abstract

28 High temperature (HT) can affect the accumulation of seed storage materials and 29 cause adverse effects on the yield and quality in rice. DNA methylation plays an 30 important role in plant growth and development. However, the temperature and DNA 31 methylation interaction on rice seed development has not been studied yet. Here, we identified a new demethylase gene OSDML4 and discovered its function on cytosine 33 demethylation to affect the endosperm formation during the grain filling. Knockout of OsDML4 induced floury endosperm only under HT, which resulted from dramatically reduced the transcription and accumulation of glutelins and $16-\mathrm{kDa}$ prolamin. The expression of two important transcription factors RISBZ1 and RPBF was significantly declined in the osdml4 mutants. The absence of OsDML4 also caused adverse effects on the formation of protein bodies (PBs), the number of PB-II was greatly decreased and incomplete PB-II with empty space and abnormally shaped PB-II were observed in the osdml4 mutants. Whole-genome bisulfite sequencing analysis of seeds at 15 days after pollination revealed much higher global methylation levels of $\mathrm{CG}, \mathrm{CHG}$ and $\mathrm{CHH}$ contexts in the osdml4 mutants compared to wild type (WT). Moreover, the methylation status of RISBZ1 promoter was hypermethylated but $R P B F$ promoter was nearly unchanged. No significant difference was detected between WT and the osdml4 mutants under room temperature. In conclusion, our study demonstrates a novel OsDML4-mediated epigenetic regulatory mechanism involving in the formation of floury endosperm, which will provide a new perspective in regulating endosperm development and the accumulation of SSPs in rice.

50 Key words: high temperature; DNA demethylation; floury endosperm; seed storage protein; rice (Oryza sativa) 


\section{Introduction}

Rice (Oryza sativa L.) is one of the most important staple crops in the world, feeding more than $60 \%$ of the population in China and providing around $40 \%$ of the total calorific needs (Cheng et al., 2007). With the continuous global warming and the emergence of extreme weather more frequently, the yield and quality of rice are more and more seriously threatened (Peng et al., 2004; Lin et al., 2005). The growth and development of rice during the grain filling stage is greatly affected by temperature. High temperature (HT) can increase grain chalkiness and total protein content, reduce grain weight, total starch content and amylose content, and affect the expression of a series genes related to the biosynthesis of seed storage materials thus leading to adverse influences on the yield and quality of rice (Yamakawa et al., 2007; Lin et al., 2010; Li et al., 2011; Cao et al., 2017; Tabassum et al., 2020; Xu et al., 2020).

Seed storage proteins (SSPs) are the important component in rice grain, which provide the nitrogen source for seed germination and nutrients for human and livestock (Kawakatsu and Takaiwa, 2010). SSPs can be divided into glutelins, prolamins, globulins and albumins according to the different solubility (Shewry and Casey, 1999). Prolamins are the major component of SSPs in most cereals such as maize (Zea mays), wheat (Triticum aestivum) and barley (Hordeum vulgare) (Shewry and Tatham, 1999). While glutelins account for the highest proportion of SSPs in rice (Takaiwa, 1999). Based on molecular mass, glutelins can fall into 57-kDa proglutelin, 37-kDa acid subunit and 22-kDa basic subunit (Yamagata et al., 1982), and fifteen glutelin genes have been identified in the rice reference genome, which can be classified into four subfamilies (GluA, GluB, GluC and GluD) (Kawakatsu et al., 2008). The prolamins fall into three groups: 10-, 13- and 16-kDa (Ogawa et al., 1987), and a total of 34 prolamin genes are present in the rice reference genome ( $\mathrm{Xu}$ and Messing, 2009). The temperature has a great effect on the accumulation of SSPs and the expression of SSP biosynthesis genes. The HT could reduce the content of 13-kDa prolamin and the expression of $13-\mathrm{kDa}$ prolamin genes, while the expression of glutelin genes was less affected (Yamakawa et al., 2007). Whereas, the HT can also increase the glutelin content and decrease the prolamin content (Ashida et al., 2013; 
Cao et al., 2017).

SSPs are synthesized on the rough endoplasmic reticulum (rER) and form two types of protein bodies (PBs) in rice endosperm cells. Spherical protein body I (PB-I) is formed by prolamins, which are retained in the ER lumen after synthesis, whereas irregular shaped protein body II (PB-II) is formed by glutelins that are transported to the protein storage vacuoles (PSVs) via the Golgi apparatus (Tian and Okita, 2014; Tian et al., 2018). Furthermore, many important regulatory factors were involved in protein folding process and the formation of PBs. OsVPE1 is essential for glutelin maturation, and the mutation of OsVPE1 influences the shape of PB-II from round to irregular (Wang et al., 2009). An ER luminal binding protein (BIP) is involved in folding and assembly of prolamin. Overexpression of BiP1 resulted in floury and shrunken endosperm with a significant reduction of SSPs and altered the morphology of PB-I (Yasuda et al., 2009). Protein disulfide isomerase (PDI) is required in glutelin trafficking and plays a critical role in proglutelin maturation and segregation of proglutelin and prolamin with the ER lumen. The absence of PDI induces floury endosperm and small ER-derived PBs containing both proglutelin precursor and prolamin (Takemoto et al., 2002; Han et al., 2012).

The endosperm specific transcription factors (TFs) have been demonstrated to regulate the expression of SSP biosynthesis genes. The basic leucine zipper factor RISBZ1/OsbZIP58 and rice prolamin binding box (RPBF) are two important regulators in rice, which can bind to specific motifs including GCN4, prolamin box (P box), ACGT and AACA in the promoter regions of SSP biosynthesis genes and activate their expression (Takaiwa et al., 1996; Wu et al., 2000; Yamamoto et al., 2006; Kawakatsu et al., 2009). Moreover, RISBZ1 can inhibit the expression of SSP genes by inducing its alternative splicing (Xu et al., 2020). In addition, OSMYB5 functions as trans-acting regulator for glutelin genes through binding to the AACA motif (Suzuki et al., 1998). Little is known about the expression patterns of SSP biosynthesis genes and the mechanism of corresponding regulatory factors under HT in rice.

DNA methylation plays a critical role in many biological processes such as 
113 embryonic development, gene regulation, structural stability of chromatin, and 114 various biotic and abiotic stress responses (Bird, 2002; Bender, 2004; Zhang et al., 115 2018). In plants, DNA methylation occurs at cytosine in $\mathrm{CG}, \mathrm{CHG}$ and $\mathrm{CHH}$ 116 sequences, and methylated DNA can be removed by demethylation (Penterman et al., 117 2007; Zhu, 2009). Six demethylase genes have been identified in rice including four 118 REPRESSOR OF SILENCING1(ROS1) ortholog genes and two DEMETER-LIKE3 119 ortholog genes (DML3) (Zemach et al., 2010). Knock-in null mutation of OsROS1a 120 leads to abortion of early-stage endosperm development, formation of irregular 121 embryos and production of no seeds (Ono et al., 2012). Knockout or knockdown of 122 DNG701(OsROS1b) can increase DNA methylation level and thus inhibit the 123 expression of the retrotransposon Tos17 (La et al., 2011). OsROS1a-mediated DNA 124 demethylation can change the number of aleurone layers and improve nutritional 125 value of rice grains (Liu et al., 2018). Hypomethylation by OsROS1a in rice 126 vegetative cells increases DNA methylation in sperm (Kim et al., 2019). 127 DML3-Mediated DNA demethylation can delay leaf senescence in Arabidopsis (Yuan 128 et al., 2020).

129 A new demethylase gene named OsDML4 was identified based on conservative 130 amino acid sequences of glycosylase domain, which is highly expressed during the 131 reproductive period (Liu et al., 2014). In order to understand whether OsDML4 may 132 have function in DNA demethylation, the knockout mutants of OsDML4 were 133 obtained using CRISPR-Cas9 genome editing system, which showed the phenotype of 134 increased grain chalkiness and floury endosperm under HT and greatly increased the 135 methylation levels in $\mathrm{CG}, \mathrm{CHG}$ and $\mathrm{CHH}$ of the whole genome only under HT. These 136 results showed that the new demethylase gene OsDML4 was involved in the 137 formation of floury endosperm through epigenetic regulatory mechanism depended on 138 temperature in rice. 


\section{Results}

\section{Grain appearance of the osdml4 mutants}

In order to investigate the function of OSDML4, the CRISPR/Cas9 system was used to generate two frameshift OsDML4 knockout mutants (Figure 1). Under HT conditions, the seeds of osdml4 mutants appeared chalky and floury in cross-section, while the WT seeds are transparent (Figure 2A-B). Scanning electron microscopy (SEM) analysis revealed that the starch granules of the osdml4 mutants were round in shape and loosely packaged, whereas those of WT are polygons and tightly packaged (Figure 2C). These morphological changes in the starch granules may account for the floury features of the osdml4 mutants to some extent, indicating that the grain filling process might be damaged in the osdml4 mutants. The storage materials in the seeds were then examined to find that the total protein content was increased and the total starch content was decreased in the osdml4 mutants (Figure 2D-E), and the amylose content of the osdml4 mutants exhibited a significant reduction compared to WT (Figure 2F). In addition, the seed length of the osdml4 mutants was significantly longer than those of WT, while the thicknesses and 1000-grain weight were considerably reduced (Figure 3A-B, D-E). No obvious difference of seed width was observed between WT and the osdml4 mutants (Figure 3C), and the main agronomic traits, with respect to plant height, effective tiller number, seed setting rate and seed number per panicle were not significantly changed (Figure S1).

As the temperature can affect the grain phenotype during the filling stage, the WT and the osdml4 mutants were then grown under RT during the filling period. The results showed that the osdml4 mutants showed similar phenotype to WT almost without chalky appearance of grain and the floury endosperm under RT (Figure S2). These results indicated that knockout of OsDML4 can result in a floury endosperm and affect the normal close packaging of starch and modulate seed size only under HT.

\section{Knockout of OsDML4 affects the accumulation of SSPs under HT}

SDS-PAGE analysis revealed that the osdml4 mutants contain much fewer amounts of $57-\mathrm{kDa}$ proglutelin than WT under HT, accompanied by a remarkable 
171 decrease in the $40-\mathrm{kDa}$ acidic and $20-\mathrm{kDa}$ basic subunits of the mature glutelins

172 (Figure 4A). In addition, the $16-\mathrm{kDa}$ prolamin and $10-\mathrm{kDa}$ prolamin was a little

173 reduced, while the $13-\mathrm{kDa}$ prolamin were considerably unchanged in comparison with

174 WT (Figure 4B). While there had no significant difference in the contents of glutelin

175 and prolamin in the mature seeds between the osdml4 mutant and WT under RT

176 (Figure 4C-D), suggested that knockout of OsDML4 influences the normal storage

177 protein inclusions to form a chalky endosperm during the maturation process of the

178 seeds only under HT.

179 OsDML4 affects the expression of SSPs biosynthesis genes and related TFs under 180 HT

181 To determine whether the alterations of the SSPs accumulation in osdml4 182 mutants will also be reflected at the transcriptional level, qRT-PCR was used to 183 determine the expression levels of SSP biosynthesis genes. Under HT conditions, the 184 expression of all glutelin genes were significantly suppressed in the osdml4 mutant. 185 The $10-\mathrm{kDa}$ and $16-\mathrm{kDa}$ prolamin genes were also greatly down regulated and the 186 13-kDa prolamin genes showed little difference between the osdml4 mutants and WT 187 (Figure 5A). Previous studies have shown that RPBF and RISBZ1 are two important 188 TFs that can positively activate the expressions of prolamin and glutelin genes. 189 Therefore, the expression levels of both TFs were investigated, and found that their 190 expression levels were significantly declined in the osdml4 mutants compared to WT 191 under HT, but no significant difference under RT (Figure 5 B and S3B). The 192 transcription levels of genes related to SSPs proper folding and assembly in the 193 post-translation process were also examined. The expression of VPE1, PDIL1-1 was 194 significantly repressed in the osdml4 mutant under HT (Figure 5B). Under RT 195 conditions, the glutelins and prolamins exhibited similar expression levels between 196 the osdml4 mutant and WT (Figure S3A). These results indicated that OsDML4 could 197 play a crucial role in the expression of SSPs biosynthesis genes under HT.

198 Because the profile of SSP was greatly altered in the osdml4 mutants, the 199 intracellular structures of developing endosperms at 15 DAP was observed by TEM to 200 determine whether this mutation also influences the PB formation. Under HT, the two 
201

202

203

204

205

206

207

208

209

210

211

212

213

214

215

216

217

218

219

220

221

222

223

224

225

226

227

228

229

230

types of PBs were readily discernible in WT. Prolamin-containing PB-I were round and surrounded by ER, while glutelin-containing PB-II were larger and irregularly shaped (Figure 6A-C). In the osdml4 mutant, the number of total PBs especially PB-II was greatly reduced (Figure 6D). In addition to the normal PB-II, some incomplete PB-II with empty space and small abnormally shaped PB-II were also observed in the osdml4 mutant (Figure 6E, F). Furthermore, much smaller PB-Is were also observed and some of which were attached to abundant vesicular structures (Figure 6F). Whereas the size, shape and number of both PB-I and PB-II were similar to those of the WT under RT (Figure S4). These results illustrated that loss function of OsDML4 has a great impact on PB formation and probably leads to the formation of floury endosperm under HT.

\section{Genome-wide hypermethylation in developing seeds of osdml4}

Since OsDML4 is a new identified demethylase gene in rice, to investigate whether OsDML4 has the function of DNA demethylation, WGBS was carried out to set up the methylomes for 15 DAP seeds of WT and the osdml4 mutants. The methylome covers more than $98 \%$ of all the genomic cytosine positions with $>20$-fold coverage per strand (Table S2). Comparative analysis of methylation levels between WT and the osdml4 mutants showed much higher global methylation levels of CG, CHG and CHH contexts in the osdml4 mutants than in WT under HT. While under RT, CG methylation levels in the osdml4 mutants were slightly lower than that of WT, and CHG and $\mathrm{CHH}$ methylation levels were slightly increased in the osdml4 mutants compared to WT (Figure 7A). We then analyzed the distribution of DNA methylation levels in different regions including promoter, 5'-UTR, exon, intron and 3'-UTR, and found that the global methylation levels of all three contexts (CG, $\mathrm{CHG}$ and $\mathrm{CHH})$ in the osdml4 mutants were sharply increased under HT. Interestingly, under RT, the osdml4 mutants had moderately lower CG methylation levels compared with WT, while CHG methylation levels were almost identical to that of WT. On the contrary, the $\mathrm{CHH}$ methylation level was increased at the promoters, but the degree of increase was much less than that under HT (Figure 7B-C). These results suggested that OsDML4 has the function of demethylation in all three contexts under HT, and loss 
231 function of OsDML4 may result in the down regulation of genes associated with 232 DMRs.

233 The Integrated Genome Browser screenshots of the WGBS data showed that the 234 DNA methylation levels of RISBZ1 promoter (182 bp from -68 to -250 relative to the 235 transcription start site) were dramatically hypermethylated under HT, while almost 236 unchanged under RT. However, no obvious difference of the DNA methylation level 237 was observed in the promoter of RPBF, glutelin genes, VPE1, BiP1 and PDIL1-1 238 under both HT and RT (Figure 8A-D, S4). The DNA methylation levels of RISBZ1 239 and RPBF promoters were confirmed by Bisulfite Genomic Sequence (BSP) (Figure 240 S5). These results suggested that the hypermethylation of RISBZ1 promoter could 241 directly reduce its expression, while others reduced gene expression was not directly 242 affected by OsDML4-mediated DNA methylation.

\section{Disscussion}

\section{Knockout of OsDML4 can induce floury endosperm}

With global warming, the negative effects of HT on the growth and development of rice is getting increasingly obvious especially on the rice yield and quality (2-3). HT can increase the formation of chalky grains with a floury endpsperm (Nakata et al., 2017). Knockout mutants of OsDML4 have a severe influence on the phenotype of the seeds with the floury endosperm only under HT (Figure 2A, B). Furthermore, the osdml4 mutants had also effects on the seed storage materials, resulting in a decreased content of total starch and amylose, and an increase of total protein content (Figure 2D-F). The starch granules of the osdml4 floury endosperm were irregularly round and loosely arranged, which was consistent with previous studies (Tabassum et al., 2020; Xu et al., 2020). These results suggested that knockout of OsDML4 not only 256 had an adverse effect on grain quality but also reduced grain yield under HT, 257 indicating that the OsDML4 gene plays a crucial role on the grain filling and is 258 hypersensitive to HT. 
261 In maize, a defective signal peptide in $22-\mathrm{kDa} \alpha$-zein and the accumulation of the

262 24-kDa $\alpha$-zein protein cause the floury endosperm phenotype (Coleman et al., 1997;

263 Gillikin et al., 1997), $\alpha$ RNAi, combined $\beta$ RNAi and $\gamma$ RNAi and the mutation of

264 16-kDa $\gamma$-zein also lead to opaque endosperm phenotypes (Kim et al., 2006; Wu and

265 Messing, 2010). In rice, the grains of RNAi mutants with simultaneous supression of

266 GluA, 13-kDa prolamin and globulin were opaque with a floury feature, resulted from

267 less accumulation of glutelin A, 13-kDa prolamin, and globulin proteins and loosely 268 packaged starch granules (Cho et al., 2016). HT will repress the deposition of the total 269 starch and amylose to reduce the grain weight and yield during grain filling stage 270 (Yamakawa and Hakata, 2010; Geigenberger, 2011; Sreenivasulu et al., 2015; Zhang 271 et al., 2017). While the effect on SSPs, HT could reduce the acccumulation and 272 expression of 13-kDa prolamin (Yamakawa et al., 2007), and increase the 273 accumulation and the expression of glutelins (Lin et al., 2010; Cao et al., 2017). The 274 loss-of-function osdml4 mutants dramatically reduced the content of glutelins and $27516-\mathrm{kDa}$ prolamins, slightly reduced the $10-\mathrm{kDa}$ prolamins, but no significantly 276 affected the content of $13-\mathrm{kDa}$ prolamins under HT (Figure 4A-B). The expression 277 levels of SSP genes were consistent with the acccumulation of SSPs (Figure 5A), 278 indicating that OsDML4 plays an important role in SSPs transcription and protein 279 accumulation.

280 The formation of floury endosperm is usually accompanied by the disruption of 281 the normal accumulation process of PBs (Wang et al., 2016; Chou et al., 2019; Ren et 282 al., 2020). Knockout of OsDML4 can significantly decrease the accumulation of 283 glutelins and greatly reduce the number and the morphology of PB-IIs under HT. The 284 incompleted PB-IIs with empty space were also found in the osdml4 mutants, 285 suggesting the existence of the restrain of vacuole formation (Figure 6A-F), which 286 was consistent with the previous study (Kawakatsu et al., 2010). Moreover, VPE1, 287 and PDIL1-1 were significantly down-regulated in the osdml4 mutant, indicating the 288 osdml4 mutant might suffer from ER stress to some extent (Figure 5B). The alteration 289 of PBs is likely to be the key factor in the formation of floury endosperm.

290 OsDML4 is a new demethylase gene and whose function on cytosine 


\section{demethylation depends on the temperature}

DNA methylation represents one of the most important epigenetic regulotary mechanisms and plays a vital role in plant growth, development and response to biotic or abiotic sitmuli (Zhang et al., 2018). DNA methylation levels can be affected by abiotic stress conditions especially the temperature. Global disrupted DNA methylation induced by HT has a significant effect on microscope abortion and anther indehiscence in cotton (Ma et al., 2018). Active DNA demethylation is mainly controled by a series of transglucosylase gene family, including DME, ROS1, DML2, and DML3, the mutations of these genes can result in genome-wide hypermethylation (Gong et al., 2002; Hsieh et al., 2009; Qian et al., 2012; Yuan et al., 2020). We indentified a new demethylase gene OsDML4 based on the conservative glycosylase domain. The WGBS analysis of 15 DAP seeds revealed that knockout of OsDML4 can dramatically hypermethylate $\mathrm{CG}, \mathrm{CHG}$ and $\mathrm{CHH}$ contexts in the whole genome under HT, while only a slightly increased methylation levels of CHG and $\mathrm{CHH}$ under RT (Figure 7), indicating that the demethylation function by OsDML4 depends on the temperature. RISBZ1 and RPBF are two essential TFs regulating SSPs exppression. Knock-down of RPBF or RISBZ1 can only cause a sligthtly reduction of SSPs, whereas their double mutants resulted in a significant reduction of SSPs (Kawakatsu et al., 2009). Nevertheless, loss function of OsbZIP58 significantly decreased SSPs under HT (Xu et al., 2020). In our study, we found that knockout of OsDML4 can significantly repress the expression of RPBF and RISBZ1 under HT, but not under RT (Figure5B, S3B). Furthemore, the methlation status of RISBZ1 promoter was hypermethylated only under HT, while the methylation level of RPBF promoter was not changed (Figure 8), suggesting that OsDML4 could regulate the expression of RISBZ1 and RPBF to make opaque endersperm, but can only hypermethylate the RISBZ1 promoter, not RPBF promoter. The mutation of OsROS1a to generate an extra transcript mOsROS1a with seven amino acids insertion exhibited thickened aleurones and the opague endosperm, which could result from DNA hypermethylation in the promoter regions of RPBF and RISBZ1 to repress their expresson (Liu et al., 2018). Therefore, OsDML4 could be a new demethylase gene that has different fuctions in 
321 demethylation from OsROS1a and the demethylation of OsDML4 depends on the 322 temperature.

323 In conclusion, knockout of OsDML4 can genome-wide hypermethylate CG, $324 \mathrm{CHG}$ and CHH contexts under HT. The expression of two TFs RISBZ1 and RPBF was 325 reduced, but only accumulation levels of glutelins and that were not directly affected 326 by DNA methylation. The reduced expression of RISBZ1 under HT could be the 327 hyper-methylation in its promoter, but the RPBF appears not to be affected directly by 328 OsDML4-mediated DNA methylation.

\section{Materials and methods}

\section{$331 \quad$ Plant materials and growth conditions}

332 The rice cultivar Nipponbare was used to grow under natural field conditions with the 333 daily mean day/night temperature $35^{\circ} \mathrm{C} / 26^{\circ} \mathrm{C}$ as $\mathrm{HT}$ conditions during the booting 334 stage. Before heading, the plants were transplanted to growth chamber with the 335 day/night temperature $28{ }^{\circ} \mathrm{C} / 22{ }^{\circ} \mathrm{C}$ as room temperature (RT) conditions. The 336 immature seeds of 15 DAP (Days after pollination) were sampled for gene expression, 337 PBs observation and whole-genome bisulfite sequencing (WGBS) analysis from both 338 HT and RT conditions.

\section{Vector construction and rice transformation}

340 The CRISPR/Cas9 binary vector pYLCRISPR/Cas9Pubi-H provided by Prof. 341 Yaoguang Liu (South China Agriculture University) was used to construct target 342 vectors for OsDML4. The online website (http://skl.scau.edu.cn/) was used to design 343 two targets for OsDML4 located at the first and the second exon of OsDML4, which 344 were ligated to OsU6a and OsU6b promoters with the oligos of 345 OsDML4-F1:5'-GCCGCAGTTCTCCGACTACGAGAC-3' and 346 OsDML4-R1:5'-AAAC GGTGGGGAACGCGGCCTTGA-3' for target 1, and 347 OsDML4-F2: 5'-GTTGACAGATCCCGCAAATACTCG-3' and OsDML4-R2: 348 5'-AAACCGAGTATTTGCGGGATCTGT-3' for target 2, respectively. The completed 349 construct was introduced into Agrobacterium tumefaciens strain EHA105 by 
350

351

352

353

354

355

356

357

358

359

360

361

362

363

364

365

366

367

368

369

370

371

372

373

374

375

376

377

378

379

electroporation. Transgenic seedlings were obtained from regenerated hygromycin-resistant callus using selection medium containing $50 \mathrm{mg} / \mathrm{L}$ hygromycin and $500 \mathrm{mg} / \mathrm{L}$ cefotaxime. Genomic DNA was extracted from transgenic plants by CTAB method to detect the mutations.

\section{Scanning electron microscopy of starch granules}

Mature rice grains were dried in an oven at $37^{\circ} \mathrm{C}$ for $7 \mathrm{~d}$ and cooled in a drying apparatus. Cross-sections of the samples were manually fractured and sputter-coated with gold palladium on the surface. Magnifications of about 1000 and 3000 were used to observe endosperm and starch granule morphology with scanning electron microscopy (SEM) (JSM-6390LV).

\section{Transmission electron microscopic observation of protein bodies}

Transverse sections (less than $1 \mathrm{~mm}$ thick) of endosperms collected at the 15 DAP were fixed in $2.5 \%$ glutaraldehyde solution with $0.2 \mathrm{M}$ phosphate buffer (pH7.2) for over $24 \mathrm{~h}$. The sections were treated as described previously (Takemoto et al., 2002), embedded in Spurr's low-viscosity and sectioned into ultra-thin sections. The ultra-thin sections were observed by transmission electron microscope (TEM) (Hitachi H7650).

\section{RNA Extraction and qRT-PCR Analysis}

Spikelets were marked on the day of flowering and picked seed samples at 15 DAP. All seed samples were immediately put into liquid nitrogen for quick freezing and stored in $-80{ }^{\circ} \mathrm{C}$ until use. Total RNAs of brown seeds were extracted by using the Plant DNA Mini Kit (Omaga) following the manufacturer's protocol. The $1 \mu \mathrm{g}$ total RNAs were used to synthesize cDNA with the PrimeScript ${ }^{\text {TMRT }}$ reagent Kit with gDNA Eraser (Takara). qRT-PCR was carried out with SYBR Premix Ex Taq II Premix (Takara) on the real-time system (Roche, Germany). Three replicates were set for each reaction, and $\beta$-Actin gene was used as the internal reference. The relative expressions were calculated by $2^{-\Delta \Delta \mathrm{Ct}}$ method. All primers used are listed in Table S1.

\section{Determination of total protein, total starch and amylose content}

The Kjeldahl method was used to determinate total protein content in rice, with slight modification according to the previous method (Kang et al., 2005). The $1 \mathrm{~g}$ of rice 
380

381

382

383

384

385

386

387

388

389

390

391

392

393

394

395

396

397

398

399

400

401

402

403

404

405

406

407

408

409

mature grain flour was put into a nitrate tube, and added $3 \mathrm{~g}$ of potassium sulfate: copper sulfate powder $(10: 1 \mathrm{w} / \mathrm{w})$, then added $8 \mathrm{~mL}$ of concentrated sulfuric acid. The total nitrogen content was calculated based on the amount of hydrochloric acid consumed by the sample. Total protein content $=$ total nitrogen content $\times 6.25$. The total starch and amylose content were measured using the amylose and total starch assay kit (G0548W, Suzhou Grace Biotechnology Co., Ltd.)

\section{Extraction of glutelin and prolamin and SDS-PAGE}

The extraction of each protein component was carried out according to the previous method (Takemoto et al., 2002) using $100 \mathrm{mg}$ mature rice grain flour. Among them, the deionized water was used for albumin extraction, $2 \% \mathrm{NaCl}(\mathrm{W} / \mathrm{V})$ for globulin extraction, $70 \%$ ethanol for prolamin extraction, and 1\% lactic acid for glutelin extraction. Glutelin and prolamin were separated by $12 \%$ SDS-PAGE.

\section{WGBS and analyses}

Total genomic DNA was extracted from the immature 15 DAP seeds of the osdml4 mutant and WT with two biological replicates using the CTAB method from both HT and RT conditions. A total amount of $100 \mathrm{ng}$ genomic DNA spiked with $0.5 \mathrm{ng}$ lambda DNA were fragmented by sonication to a mean size of $250 \mathrm{bp}$ with Covaris S220. The DNA fragments were then treated with bisulfite using EZ DNA Methylation-GoldTM Kit (Zymo Research), and libraries were constructed by Novogene Corporation (Beijing, China). Subsequently, pair-end sequencing was performed using the Illumina Novaseq platform (Illumina, CA, USA).

\section{DNA methylation validated by Bisulfite Sequencing}

Bisulfite sequencing PCR was performed using the same genomic DNA as for WGBS. In brief, 200 ng of DNA was treated with sodium bisulfite using the Qiagen Kit. The primers were designed using the MethPrimer online software (http://www.urogene.org/ methprimer2/index.html) (Table S1). For each PCR reaction, $1 \mathrm{ul}$ of bisulfite-treated DNA was used in a $20 \mathrm{ul}$ reaction. PCR products were purified using Zymoclean Gel DNA Recovery kit and subcloned into pTA2 vector. For each DMR locus in the WT or the osdml4 mutant, more than 10 independent clones were sequenced by Sanger method. The sequencing data were analyzed using the Bisulfite 
410 Analysis online software (http://katahdin.mssm.edu/kismeth/revpage.pl).

411

\section{Acknowledgements}

413 This study was supported by the Talent Project of Zhejiang Province (2019R52033 to

414 HMZ) and Zhejiang Zhengjingyuan Pharmacy Chain Co., Ltd. (H20151699 and 415 H20151788 to JHX).

416

417 Author contributions

418 JHX, HMZ and YY designed research; YY, CL, JRK, ZKY, JY, CCR, HMZ and JHX

419 performed research; YY, CL, MSA conducted the field and growth chamber work; YY, 420 ZL, JJZ, MHD, HMZ and JHX analyzed data; YY and JHX wrote and edited the 421 manuscript.

422

423 Declaration of competing interest

424 The authors declared no conflict of interest.

426 Figure legends

427 Figure 1. CRISPR/Cas9-induced mutations in the OsDML4 gene. (A) The 428 Schematic diagram of the OsDML4 gene. The UTRs, exons and introns are indicated 429 by gray rectangles, black rectangles and black lines, and the start codon (ATG) and 430 stop codon (TGA) and their positions were showed. (B) The sequences of the two 431 targets are shown with the protospacer adjacent motif (PAM) sequences labeled in 432 blue color. The editing genotypes are identified by sanger sequencing and aligned 433 with wild type (WT), the deletions and insertions are indicated by red dashes red 434 letters.

435

436 Figure 2. Appearance of the WT and the osdml4 mutants mature seeds under HT.

437 (A) External appearance of brown seeds from WT and the osdml4 mutants. (B) 438 Transverse sections of WT and the osdml4 mutant dry seeds. (C) Scanning electron 439 micrographs of mature endosperms of WT and the osdml4 mutants (up, scale bar = 
$44010 \mu \mathrm{m} ;$ down, scale bar $=3 \mu \mathrm{m})$. (D) Total protein content in mature seeds of WT and

441 the osdml4 mutants. (E) Total starch content in mature seeds of WT and the osdml4 442 mutants. (F) Amylose content of WT and the osdml4 mutants. Data are the means \pm $443 \mathrm{SD}$ of three biological replicates. Significant differences were determined using 444 two-tailed Student's t-test $(* \mathrm{p}<0.05, * * \mathrm{p}<0.01)$.

445

446 Figure 3. Grain shape analyses of the osdml4 mutants under HT. (A) The Seed 447 phenotype of the wild type and osdml4 mutants. The statistic analyses of (B) seed 448 length, (C) seed width, (D) seed thicknesses, and (E) 1000-grain weight of WT and 449 osdml4 mutants. Data are the means \pm SD of three biological replicates. Significant 450 differences were determined using two-tailed Student's t-test $\left(* \mathrm{p}<0.05,{ }^{*} \mathrm{p}<0.01\right)$.

Figure 4. SDS-PAGE analysis of seed storage proteins in mature seeds of WT and the osdml4 mutants. (A) glutelins and (B) prolamins in WT and osdml4 mutants under HT. (C) glutelins and (D) prolamins in WT and osdml4 mutants under RT. The seed storage proteins were extracted according to the previous method, and were separated by $12 \%$ SDS-PAGE.

Figure 5. qRT-PCR analysis of SSP genes and their regulatory factors in 15 DAP immature seeds of WT and the osdml4 mutant under HT. (A) SSP genes, (B) SSP regulatory factors. Data are the means \pm SD of three biological replicates. Significant differences were determined using two-tailed Student's $t$-test $\left({ }^{*} \mathrm{p}<0.05, * * \mathrm{p}<0.01\right)$.

Figure 6. Transmission electron microscope of protein bodies in developing endosperm at 15 DAP under HT. (A-C) WT, (D-F) the osdml4 mutant. Scale bar = $10 \mu \mathrm{m}$ in $(\mathrm{A}, \mathrm{D})$ and $1 \mu \mathrm{m}$ in $(\mathrm{B}, \mathrm{C}, \mathrm{E}, \mathrm{F})$. IPBII, incomplete PBII with empty space; ASPBII: abnormally shaped PBII. 
469

470

471

472

473

474

475

476

477

478

479

480

481

482

483

484

485

486

487

488

489

490

491

492

493

494

495

496

497

498

under HT and RT. (A) DNA methylation levels in CG, CHG and CHH contexts in WT and the osdml4 mutant seeds at 15 DAP under HT and RT. The average methylation levels in $\mathrm{CG}, \mathrm{CHG}$ and $\mathrm{CHH}$ contexts of different genic regions in WT and the osdml4 mutant seeds at 15 DAP under (B) HT and (C) RT.

Figure 8. The DNA methylation levels in the RISBZ1 and RPBF. The integrated genome browser screenshots of the WGBS data of the DNA methylation levels of (A) RISBZ1 and (C) RPBF promoters, the statistic analysis of the DNA methylation levels of (C) RISBZ1 and (D) RPBF promoters in WT and the osdml4 mutant seeds at 15 DAP under HT and RT. Dashed frames indicate the hypermethylated regions in the osdml4 mutants.

\section{Supplemental Figure legends}

Figure S1. Phenotypes comparison of the osdml4 mutants and WT at the mature stage under HT. (A) Plant appearance of the osdml4 mutants and WT. (B) Plant height of the osdml4 mutants and WT. (C) Tiller numbers per plant of the osdml4 mutants and WT. (D) Seed setting rate of the osdml4 mutants and WT. (E) Seed numbers per panicle of the osdml4 mutants and WT. Data are the means \pm SD of three biological replicates. Significant differences were determined using two-tailed Student's t-test $(* \mathrm{p}<0.05, * * \mathrm{p}<0.01)$.

Figure S2. Appearance of the WT and osdml4 mutants mature seeds under RT. (A) External appearance of brown seeds. (B) Transverse sections of the dry seeds.

Figure S3. Expression levels of genes related to seed storage proteins biosynthesis (A) and transmission electron microscope (TEM) of protein bodies in developing endosperm at 15 DAF under RT (B-E). B and C, WT; D and E, osdml4 mutants. Scale bars $=10 \mu \mathrm{m}$ in $(\mathrm{A}, \mathrm{B})$ and $2 \mu \mathrm{m}$ in $(\mathrm{C}, \mathrm{D})$. 
499 Figure S4. The DNA methylation levels in the promoter regions of glutelin genes

500 (GluA1, GluB1, GluC, and GluD) and their regulatory factors (VPE1, BiP1 and $501 \quad$ PDIL1-1) in WT and osdml4 mutants under HT and RT at 15 DAP.

502

503 Figure S5. DNA methylation levels of RISBZ1 and RPBF promoters obtained by 504 BSP.

505

506 Supplemental Table 1 The sequences of primers used in this study

507

508 Supplemental Table 2 Details of data quality control statistics of WGBS 509 sequencing generated libraries 


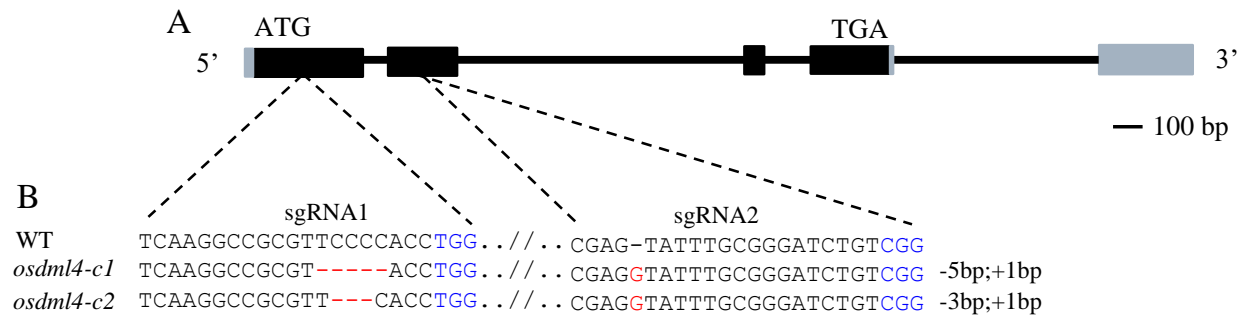

Figure 1. CRISPR/Cas9-induced mutations in the OsDML4 gene. (A) The Schematic diagram of the OsDML4 gene. The UTRs, exons and introns are indicated by gray rectangles, black rectangles and black lines, and the start codon (ATG) and stop codon (TGA) and their positions were showed. (B) The sequences of the two targets are shown with the protospacer adjacent motif (PAM) sequences labeled in blue color. The editing genotypes are identified by sanger sequencing and aligned with wild type (WT), the deletions and insertions are indicated by red dashes red letters. 


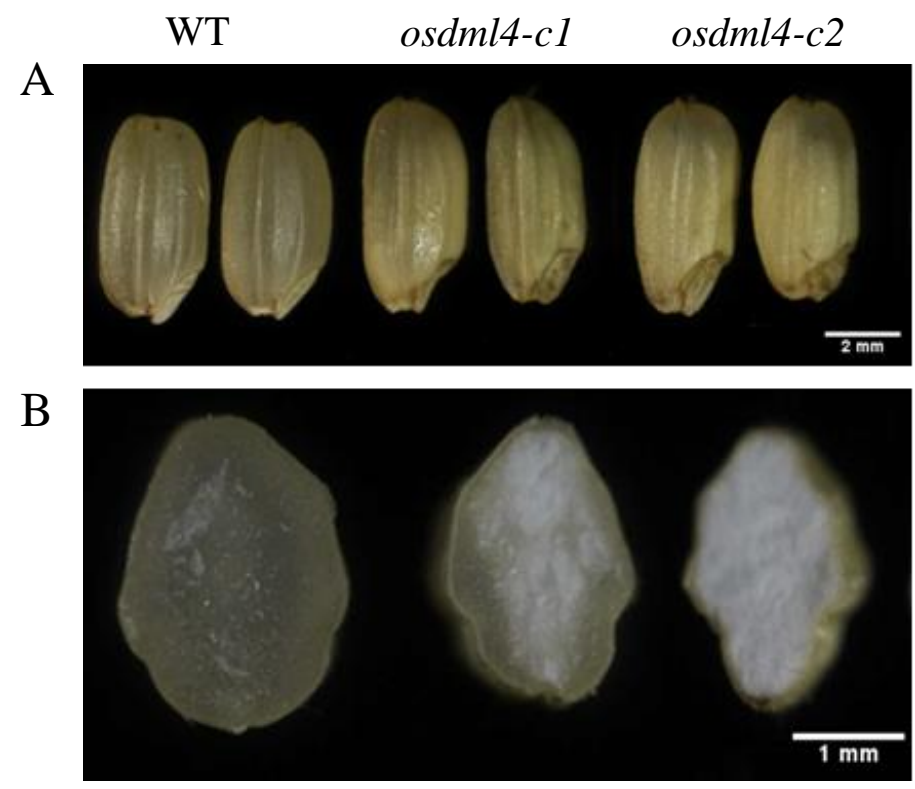

C
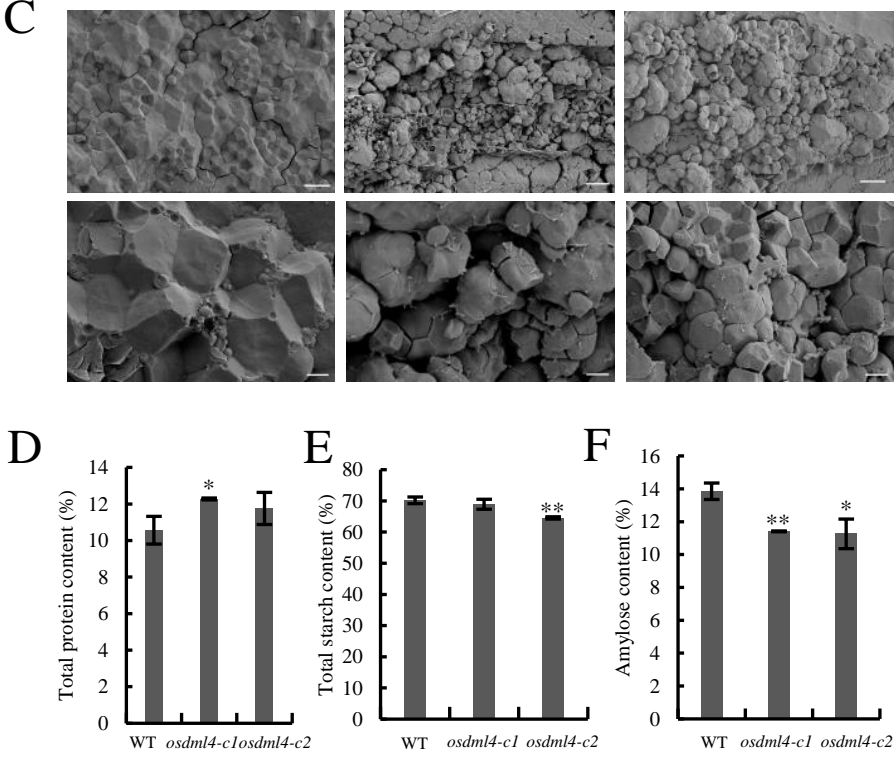

Figure 2. Appearance of the WT and the osdml4 mutants mature seeds under HT. (A) External appearance of brown seeds from WT and the osdml4 mutants. (B) Transverse sections of WT and the osdml4 mutant dry seeds. (C) Scanning electron micrographs of mature endosperms of WT and the osdml4 mutants (up, scale bar = $10 \mu \mathrm{m}$; down, scale bar $=3 \mu \mathrm{m}$ ). (D) Total protein content in mature seeds of WT and the osdml4 mutants. (E) Total starch content in mature seeds of WT and the osdml4 mutants. (F) Amylose content of WT and the osdml4 mutants. Data are the means \pm SD of three biological replicates. Significant differences were determined using twotailed Student's $t$-test $(* \mathrm{p}<0.05, * * \mathrm{p}<0.01)$. 


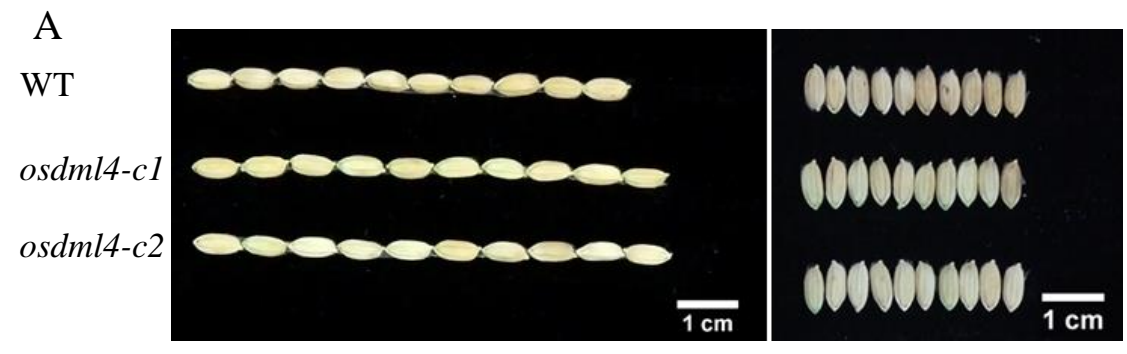

B

$\mathrm{C}$
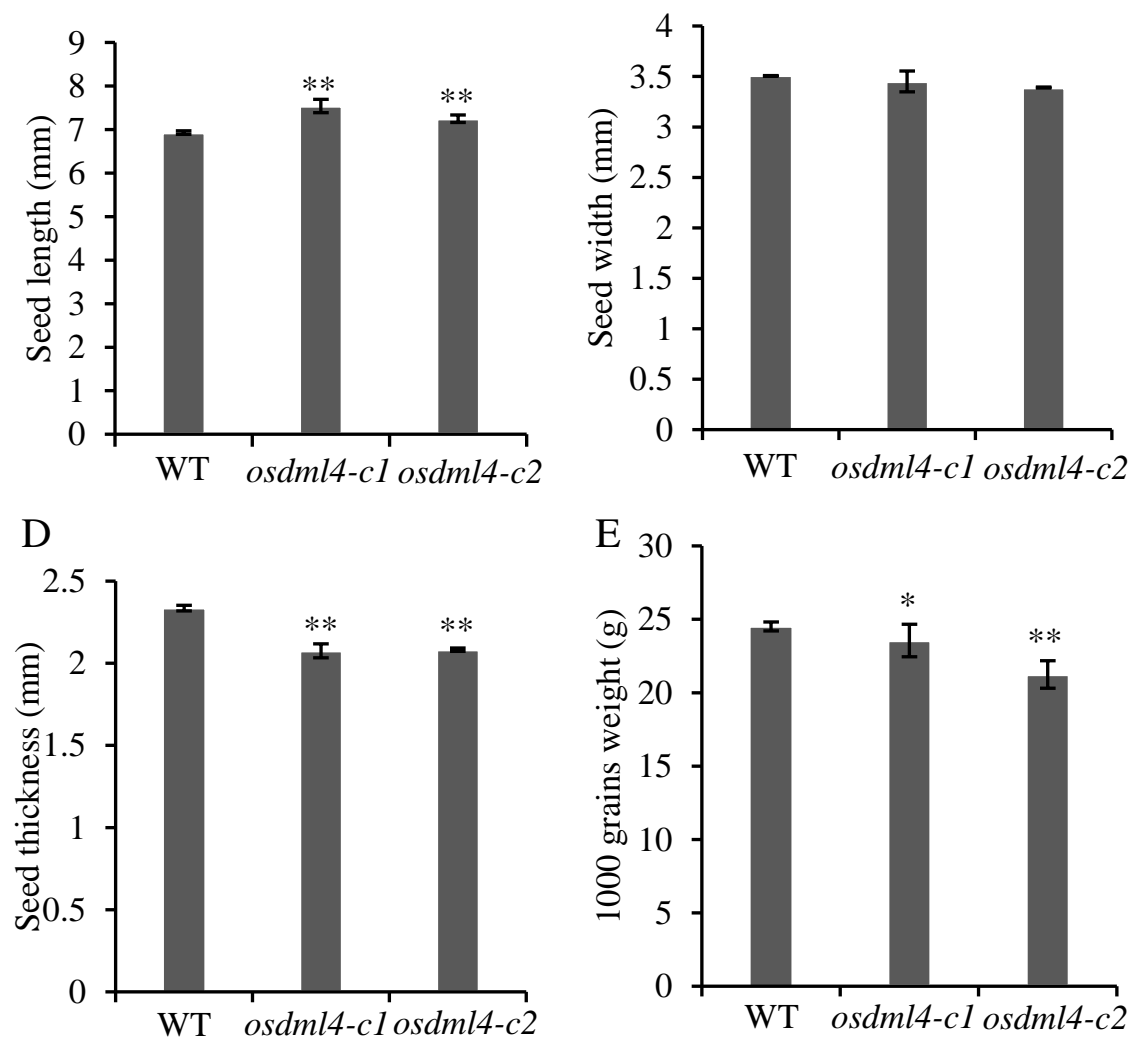

Figure 3. Grain shape analyses of the osdml4 mutants under HT. (A) The Seed phenotype of the wild type and $o s d m l 4$ mutants. The statistic analyses of (B) seed length, (C) seed width, (D) seed thicknesses, and (E) 1000-grain weight of WT and osdml4 mutants. Data are the means \pm SD of three biological replicates. Significant differences were determined using two-tailed Student's $t$-test $(* \mathrm{p}<0.05$, **p<0.01). 


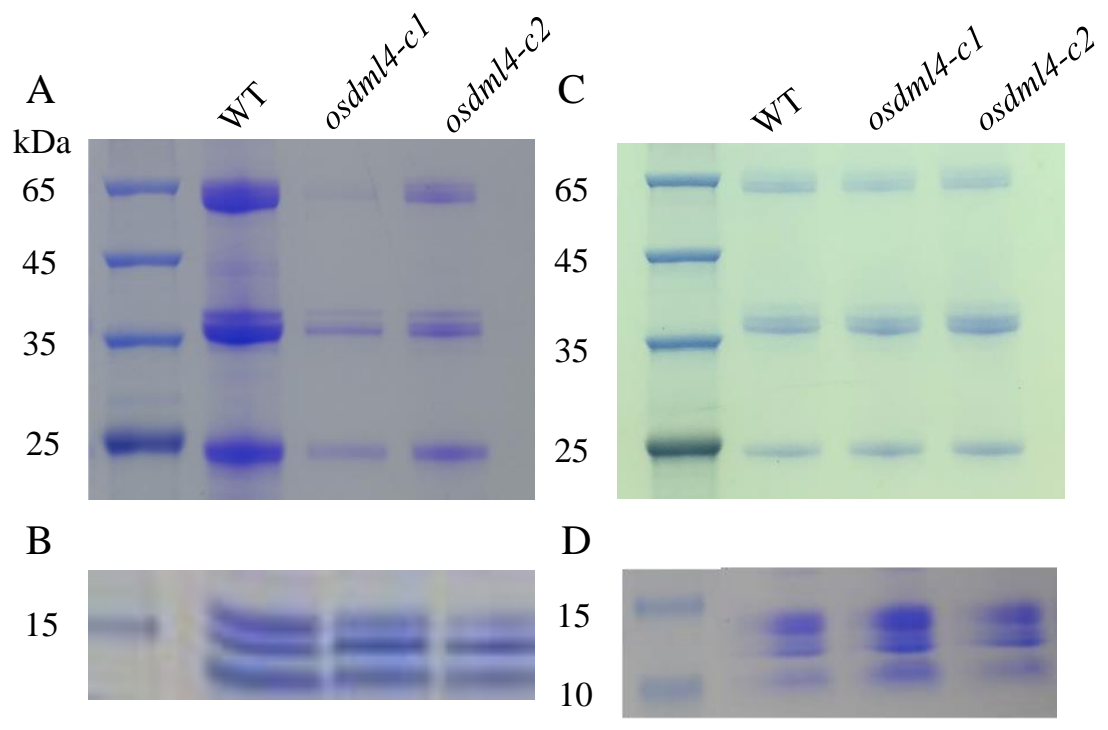

Figure 4. SDS-PAGE analysis of seed storage proteins in mature seeds of WT and the osdml4 mutants. (A) glutelins and (B) prolamins in WT and osdml4 mutants under HT. (C) glutelins and (D) prolamins in WT and osdml4 mutants under RT. The seed storage proteins were extracted according to the previous method, and were separated by $12 \%$ SDS-PAGE. 

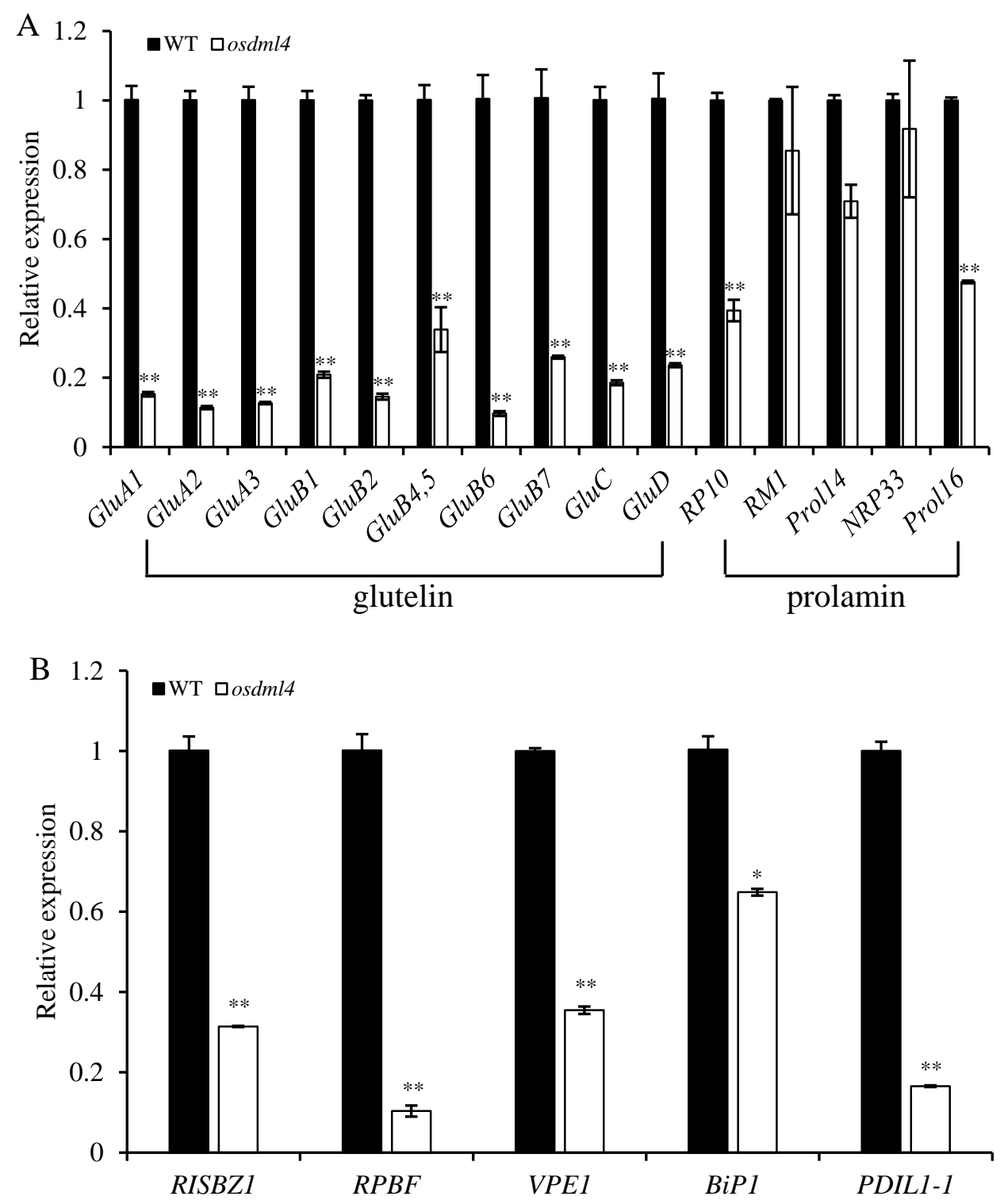

Figure 5. qRT-PCR analysis of SSP genes and their regulatory factors in 15 DAP immature seeds of WT and the osdml4 mutant under HT. (A) SSP genes, (B) SSP regulatory factors. Data are the means \pm SD of three biological replicates. Significant differences were determined using two-tailed Student's $t$ test $(* \mathrm{p}<0.05, * * \mathrm{p}<0.01)$. 

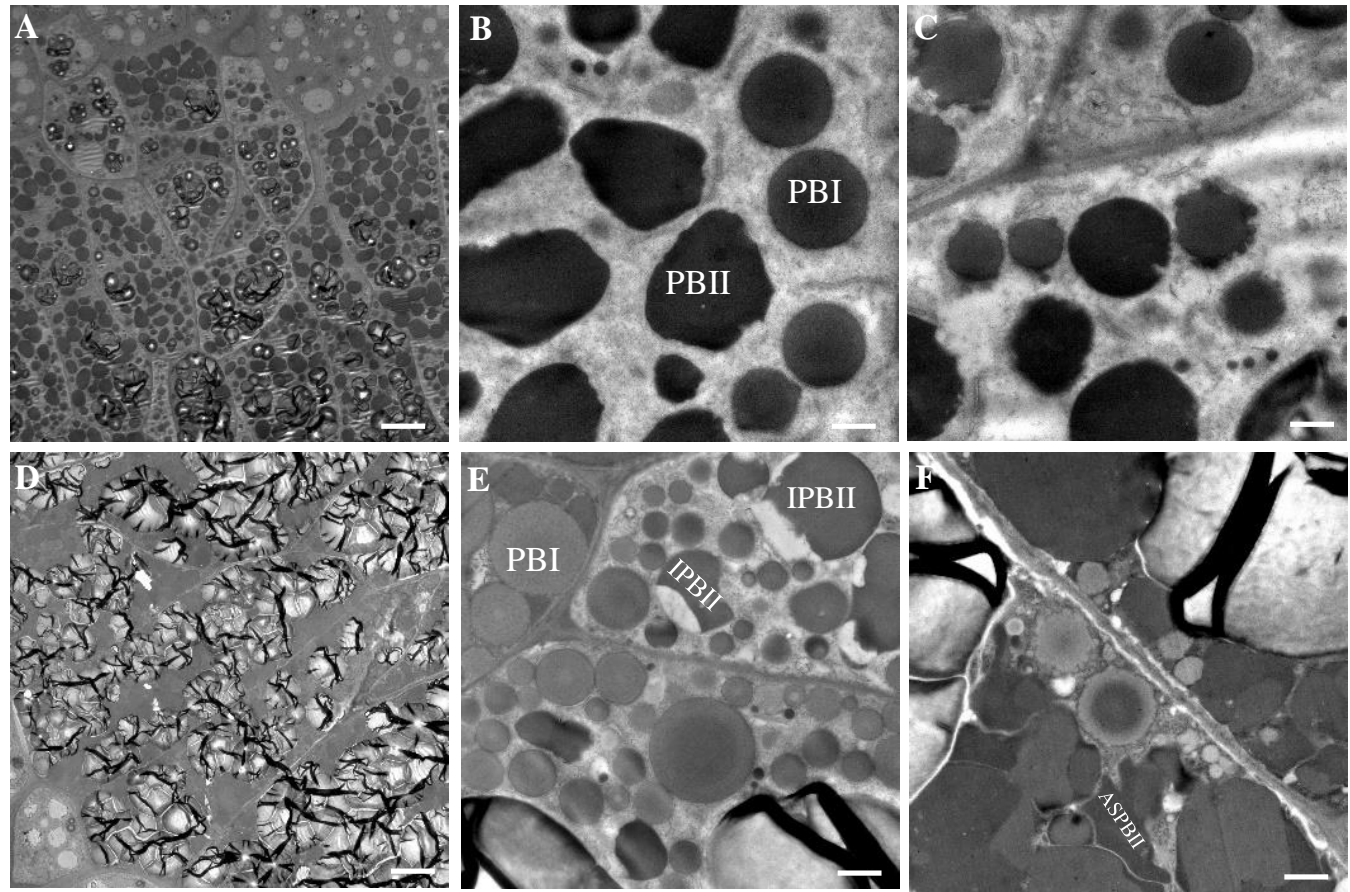

Figure 6. Transmission electron microscope of protein bodies in developing endosperm at 15 DAP under HT. (A-C) WT, (D-F) the osdml4 mutant. Scale bar $=10 \mu \mathrm{m}$ in (A, D) and $1 \mu \mathrm{m}$ in (B, C, E, F). IPBII, incomplete PBII with empty space; ASPBII: abnormally shaped PBII. 

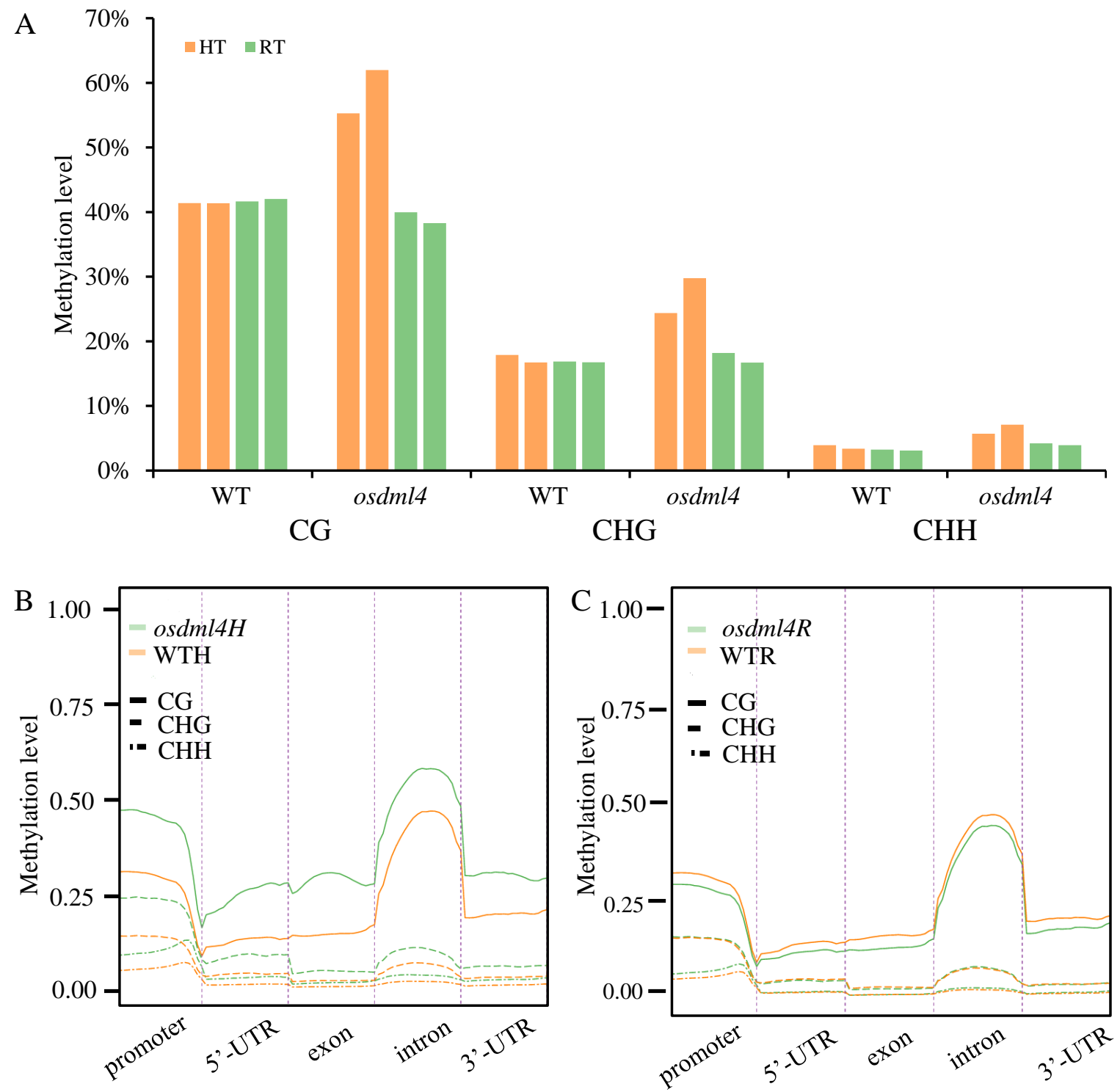

Figure 7. DNA methylation patter in 15 DAP seeds of WT and the osdml4 mutant under HT and RT. (A) DNA methylation levels in CG, CHG and CHH contexts in WT and the osdml4 mutant seeds at 15 DAP under HT and RT. The average methylation levels in CG, CHG and $\mathrm{CHH}$ contexts of different genic regions in WT and the osdml4 mutant seeds at $15 \mathrm{DAP}$ under (B) HT and (C) RT. 

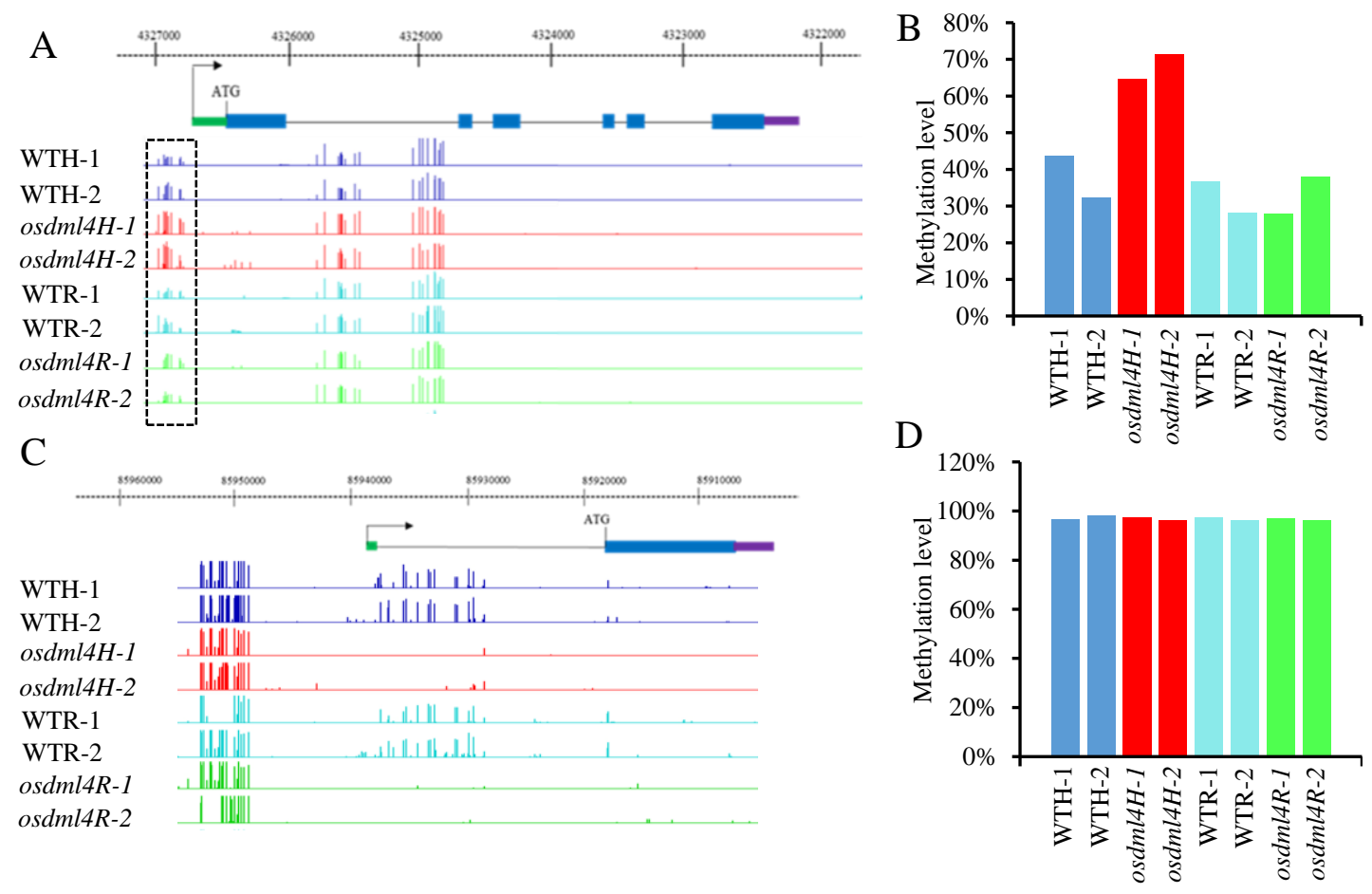

Figure 8. The DNA methylation levels in the RISBZ1 and RPBF. The integrated genome browser screenshots of the WGBS data of the DNA methylation levels of (A) RISBZ1 and (C) RPBF promoters, the statistic analysis of the DNA methylation levels of (C) RISBZ1 and (D) $R P B F$ promoters in WT and the osdml4 mutant seeds at 15 DAP under HT and RT. Dashed frames indicate the hypermethylated regions in the osdml4 mutants. 


\section{Parsed Citations}

Ashida K, Araki E, Maruyama-Funatsuki W, Fujimoto H, Ikegami M (2013) Temperature during grain ripening affects the ratio of type-Il/type-I protein body and starch pasting properties of rice (Oryza sativa L.). Journal of Cereal Science 57: 153-159

Google Scholar: Author Only Title Only Author and Title

Bender J (2004) DNA methylation and epigenetics. Annu Rev Plant Biol 55: 41-68

Google Scholar: Author Only Title Only Author and Title

Bird A (2002) DNA methylation patterns and epigenetic memory. Genes Dev 16: 6-21

Google Scholar: Author Only Title Only Author and Title

Cao ZZ, Zhao Q, Pan G, Wei KS, Zhou LJ, Cheng FM (2017) Comprehensive expression of various genes involved in storage protein synthesis in filling rice grain as affected by high temperature. Plant Growth Regul 81: 477-488

Google Scholar: Author Only Title Only Author and Title

Cheng SH, Cao LY, Zhuang JY, Chen SG, Zhan XD, Fan YY, Zhu DF, Min SK (2007) Super hybrid rice breeding in China:

Achievements and prospects. J Integr Plant Biol 49: 805-810

Google Scholar: Author Only Title Only Author and Title

Cho K, Lee HJ, Jo YM, Lim SH, Rakwal R, Lee JY, Kim YM (2016) RNAInterference-Mediated Simultaneous Suppression of Seed Storage Proteins in Rice Grains. Front Plant Sci 7: 1624

Google Scholar: Author Only Title Only Author and Title

Chou HL, Tian L, Fukuda M, Kumamaru T, Okita TW(2019) The Role of RNA-Binding Protein OsTudor-SN in Post-Transcriptional Regulation of Seed Storage Proteins and Endosperm Development. Plant Cell Physiol 60: 2193-2205

Google Scholar: Author Only Title Only Author and Title

Coleman CE, Clore AM, Ranch JP, Higgins R, Lopes MA, Larkins BA(1997) Expression of a mutant alpha-zein creates the floury2 phenotype in transgenic maize. Proc Natl Acad Sci U S A94: 7094-7097

Google Scholar: Author Only Title Only Author and Title

Geigenberger P (2011) Regulation of starch biosynthesis in response to a fluctuating environment. Plant Physiol 155: 1566-1577 Google Scholar: Author Only Title Only Author and Title

Gillikin JW, Zhang F, Coleman CE, Bass HW, Larkins BA, Boston RS (1997) Adefective signal peptide tethers the floury-2 zein to the endoplasmic reticulum membrane. Plant Physiol 114: 345-352

Google Scholar: Author Only Title Only Author and Title

Gong Z, Morales-Ruiz T, Ariza RR, Roldan-Arjona T, David L, Zhu JK (2002) ROS1, a repressor of transcriptional gene silencing in Arabidopsis, encodes a DNA glycosylase/lyase. Cell 111: 803-814

Google Scholar: Author Only Title Only Author and Title

Han X, Wang Y, Liu X, Jiang L, Ren Y, Liu F, Peng C, Li J, Jin X, Wu F, Wang J, Guo X, Zhang X, Cheng Z, Wan J (2012) The failure to express a protein disulphide isomerase-like protein results in a floury endosperm and an endoplasmic reticulum stress response in rice. J Exp Bot 63: 121-130

Google Scholar: Author Only Title Only Author and Title

Hsieh TF, Ibarra CA, Silva P, Zemach A, Eshed-Williams L, Fischer RL, Zlberman D (2009) Genome-wide demethylation of Arabidopsis endosperm Science 324: 1451-1454

Google Scholar: Author Only Title Only Author and Title

Kang HG, Park S, Matsuoka M, An G (2005) White-core endosperm floury endosperm-4 in rice is generated by knockout mutations in the C-type pyruvate orthophosphate dikinase gene (OsPPDKB). Plant J 42: 901-911

Google Scholar: Author Only Title Only Author and Title

Kawakatsu T, Hirose S, Yasuda H, Takaiwa F (2010) Reducing rice seed storage protein accumulation leads to changes in nutrient quality and storage organelle formation. Plant Physiol 154: 1842-1854

Google Scholar: Author Only Title Only Author and Title

Kawakatsu T, Takaiwa F (2010) Cereal seed storage protein synthesis: fundamental processes for recombinant protein production in cereal grains. Plant Biotechnol J 8: 939-953

Google Scholar: Author Only Title Only Author and Title

Kawakatsu T, Yamamoto MP, Hirose S, Yano M, Takaiwa F (2008) Characterization of a new rice glutelin gene GluD-1 expressed in the starchy endosperm J Exp Bot 59: 4233-4245

Google Scholar: Author Only Title Only Author and Title

Kawakatsu T, Yamamoto MP, Touno SM, Yasuda H, Takaiwa F (2009) Compensation and interaction between RISBZ1 and RPBF during grain filling in rice. Plant J 59: 908-920 
Google Scholar: Author Only Title Only Author and Title

Kim CS, Gibbon BC, Gillikin JW, Larkins BA, Boston RS, Jung R (2006) The maize Mucronate mutation is a deletion in the 16-kDa gamma-zein gene that induces the unfolded protein response. Plant $\mathrm{J}$ 48: $440-451$

Google Scholar: Author Only Title Only Author and Title

Kim MY, Ono A Scholten S, Kinoshita T, Zlberman D, Okamoto T, Fischer RL (2019) DNA demethylation by ROS1a in rice vegetative cells promotes methylation in sperm Proc Natl Acad Sci U S A116: 9652-9657

Google Scholar: Author Only Title Only Author and Title

La H, Ding B, Mishra GP, Zhou B, Yang H, Bellizzi Mdel R, Chen S, Meyers BC, Peng Z, Zhu JK, Wang GL (2011) A5methylcytosine DNA glycosylase/lyase demethylates the retrotransposon Tos17 and promotes its transposition in rice. Proc Natl Acad Sci U S A 108: 15498-15503

Google Scholar: Author Only Title Only Author and Title

Li H, Chen Z, Hu M, Wang Z, Hua H, Yin C, Zeng H (2011) Different effects of night versus day high temperature on rice quality and accumulation profiling of rice grain proteins during grain filling. Plant Cell Rep 30: 1641-1659

Google Scholar: Author Only Title Only Author and Title

Lin CJ, Li CY, Lin SK, Yang FH, Huang JJ, Liu YH, Lur HS (2010) Influence of high temperature during grain filling on the accumulation of storage proteins and grain quality in rice (Oryza sativa L.). J Agric Food Chem 58: 10545-10552

Google Scholar: Author Only Title Only Author and Title

Lin SK, Chang MC, Tsai YG, Lur HS (2005) Proteomic analysis of the expression of proteins related to rice quality during caryopsis development and the effect of high temperature on expression. Proteomics 5: 2140-2156

Google Scholar: Author Only Title Only Author and Title

Liu J, Wu X, Yao X, Yu R, Larkin PJ, Liu CM (2018) Mutations in the DNA demethylase OsROS1 result in a thickened aleurone and improved nutritional value in rice grains. Proc Natl Acad Sci U S A 115: 11327-11332

Google Scholar: Author Only Title Only Author and Title

Liu Q, Xue Q, Xu J (2014) [Phylogenetic analysis of DNA demethylase genes in angiosperm]. Yi Chuan 36: 276-285

Google Scholar: Author Only Title Only Author and Title

Ma Y, Min L, Wang M, Wang C, Zhao Y, Li Y, Fang Q, Wu Y, Xie S, Ding Y, Su X, Hu Q, Zhang Q, Li X, Zhang X (2018) Disrupted Genome Methylation in Response to High Temperature Has Distinct Affects on Microspore Abortion and Anther Indehiscence. Plant Cell 30: 1387-1403

Google Scholar: Author Only Title Only Author and Title

Nakata M, Fukamatsu Y, Miyashita T, Hakata M, Kimura R, Nakata Y, Kuroda M, Yamaguchi T, Yamakawa H (2017) High

Temperature-Induced Expression of Rice alpha-Amylases in Developing Endosperm Produces Chalky Grains. Front Plant Sci 8: 2089

Google Scholar: Author Only Title Only Author and Title

Ogawa M, Kumamaru T, Satoh H, Iwata N, Omura T, Kasai Z, Tanaka K (1987) Purification of Protein Body-I of Rice Seed and Its Polypeptide Composition. Plant and Cell Physiology 28: 1517-1527

Google Scholar: Author Only Title Only Author and Title

Ono A, Yamaguchi K, Fukada-Tanaka S, Terada R, Mitsui T, lida S (2012) A null mutation of ROS1a for DNA demethylation in rice is not transmittable to progeny. Plant J 71: 564-574

Google Scholar: Author Only Title Only Author and Title

Peng S, Huang J, Sheehy JE, Laza RC, Visperas RM, Zhong X, Centeno GS, Khush GS, Cassman KG (2004) Rice yields decline with higher night temperature from global warming. Proc Natl Acad Sci U S A 101: 9971-9975

Google Scholar: Author Only Title Only Author and Title

Penterman J, Zlberman D, Huh JH, Ballinger T, Henikoff S, Fischer RL (2007) DNA demethylation in the Arabidopsis genome.

Proc Natl Acad Sci U S A 104: 6752-6757

Google Scholar: Author Only Title Only Author and Title

Qian W, Miki D, Zhang H, Liu Y, Zhang X, Tang K, Kan Y, La H, Li X, Li S, Zhu X, Shi X, Zhang K, Pontes O, Chen X, Liu R, Gong Z, Zhu JK (2012) A histone acetyltransferase regulates active DNAdemethylation in Arabidopsis. Science 336: 1445-1448

Google Scholar: Author Only Title Only Author and Title

Ren Y, Wang Y, Pan T, Wang Y, Wang Y, Gan L, Wei Z, Wang F, Wu M, Jing R, Wang J, Wan G, Bao X, Zhang B, Zhang P, Zhang Y, Ji Y, Lei C, Zhang X, Cheng Z, Lin Q, Zhu S, Zhao Z, Wang J, Wu C, Qiu L, Wang H, Wan J (2020) GPA5 Encodes a Rab5a Effector Required for Post-Golgi Trafficking of Rice Storage Proteins. Plant Cell 32: 758-777

Google Scholar: Author Only Title Only Author and Title

Shewry PR, Casey R (1999) Seed Proteins. In PR Shewry, R Casey, eds, Seed Proteins. Springer Netherlands, Dordrecht, pp 1-10 Google Scholar: Author Only Title Only Author and Title 
Shewry PR, Tatham AS (1999) The Characteristics, Structures and Evolutionary Relationships of Prolamins. In PR Shewry, R Casey, eds, Seed Proteins. Springer Netherlands, Dordrecht, pp 11-33

Google Scholar: Author Only Title Only Author and Title

Sreenivasulu N, Butardo VM, Jr., Misra G, Cuevas RP, Anacleto R, Kavi Kishor PB (2015) Designing climate-resilient rice with ideal grain quality suited for high-temperature stress. J Exp Bot 66: 1737-1748

Google Scholar: Author Only Title Only Author and Title

Suzuki A, Wu CY, Washida H, Takaiwa F (1998) Rice MYB protein OSMYB5 specifically binds to the AACAmotif conserved among promoters of genes for storage protein glutelin. Plant Cell Physiol 39: 555-559

Google Scholar: Author Only Title Only Author and Title

Tabassum R, Dosaka T, Ichida H, Morita R, Ding Y, Abe T, Katsube-Tanaka T (2020) FLOURY ENDOSPERM11-2 encodes plastid HSP70-2 involved with the temperature-dependent chalkiness of rice (Oryza sativa L.) grains. Plant J 103: 604-616

Google Scholar: Author Only Title Only Author and Title

Takaiwa F (1999) Structure and expression of rice seed protein genes. In K Shimamoto, ed, Molecular biology of rice. SpringerVerlag Tokyo, Tokyo, Japan, pp 178-199

Google Scholar: Author Only Title Only Author and Title

Takaiwa F, Yamanouchi U, Yoshihara T, Washida H, Tanabe F, Kato A, Yamada K (1996) Characterization of common cis-regulatory elements responsible for the endosperm-specific expression of members of the rice glutelin multigene family. Plant Mol Biol 30: 1207-1221

Google Scholar: Author Only Title Only Author and Title

Takemoto Y, Coughlan SJ, Okita TW, Satoh H, Ogawa M, Kumamaru T (2002) The rice mutant esp2 greatly accumulates the glutelin precursor and deletes the protein disulfide isomerase. Plant Physiol 128: 1212-1222

Google Scholar: Author Only Title Only Author and Title

Tian L, Chou HL, Zhang L, Hwang SK, Starkenburg SR, Doroshenk KA, Kumamaru T, Okita TW (2018) RNABinding Protein RBP-P Is Required for Glutelin and Prolamine mRNA Localization in Rice Endosperm Cells. Plant Cell 30: 2529-2552

Google Scholar: Author Only Title Only Author and Title

Tian L, Okita TW (2014) mRNAbased protein targeting to the endoplasmic reticulum and chloroplasts in plant cells. Curr Opin Plant Biol 22: 77-85

Google Scholar: Author Only Title Only Author and Title

Wang Y, Liu F, Ren Y, Wang Y, Liu X, Long W, Wang D, Zhu J, Zhu X, Jing R, Wu M, Hao Y, Jiang L, Wang C, Wang H, Bao Y, Wan J (2016) GOLGI TRANSPORT 1B Regulates Protein Export from the Endoplasmic Reticulum in Rice Endosperm Cells. The Plant Cell 28: 2850-2865

Google Scholar: Author Only Title Only Author and Title

Wang Y, Zhu S, Liu S, Jiang L, Chen L, Ren Y, Han X, Liu F, Ji S, Liu X, Wan J (2009) The vacuolar processing enzyme OsVPE1 is required for efficient glutelin processing in rice. Plant $\mathrm{J}$ 58: 606-617

Google Scholar: Author Only Title Only Author and Title

Wu C, Washida H, Onodera Y, Harada K, Takaiwa F (2000) Quantitative nature of the Prolamin-box, ACGT and AACA motifs in a rice glutelin gene promoter: minimal cis-element requirements for endosperm-specific gene expression. Plant J 23: 415-421

Google Scholar: Author Only Title Only Author and Title

Wu Y, Messing J (2010) RNA interference-mediated change in protein body morphology and seed opacity through loss of different zein proteins. Plant Physiol 153: 337-347

Google Scholar: Author Only Title Only Author and Title

Xu H, Li X, Zhang H, Wang L, Zhu Z, Gao J, Li C, Zhu Y (2020) High temperature inhibits the accumulation of storage materials by inducing alternative splicing of OsbZP58 during filling stage in rice. Plant Cell Environ 43: 1879-1896

Google Scholar: Author Only Title Only Author and Title

Xu JH, Messing J (2009) Amplification of prolamin storage protein genes in different subfamilies of the Poaceae. Theor Appl Genet 119: 1397-1412

Google Scholar: Author Only Title Only Author and Title

Yamagata H, Sugimoto T, Tanaka K, Kasai Z(1982) Biosynthesis of storage proteins in developing rice seeds. Plant Physiol 70: 1094-1100

Google Scholar: Author Only Title Only Author and Title

Yamakawa H, Hakata M (2010) Atlas of rice grain filling-related metabolism under high temperature: joint analysis of metabolome and transcriptome demonstrated inhibition of starch accumulation and induction of amino acid accumulation. Plant Cell Physiol 51: 795-809

Google Scholar: Author Only Title Only Author and Title 
Yamakawa H, Hirose T, Kuroda M, Yamaguchi T (2007) Comprehensive expression profiling of rice grain filling-related genes under high temperature using DNA microarray. Plant Physiol 144: 258-277

Google Scholar: Author Only Title Only Author and Title

Yamamoto MP, Onodera Y, Touno SM, Takaiwa F (2006) Synergism between RPBF Dof and RISBZ1 bZP activators in the regulation of rice seed expression genes. Plant Physiol 141: 1694-1707

Google Scholar: Author Only Title Only Author and Title

Yasuda H, Hirose S, Kawakatsu T, Wakasa Y, Takaiwa F (2009) Overexpression of BiP has inhibitory effects on the accumulation of seed storage proteins in endosperm cells of rice. Plant Cell Physiol 50: 1532-1543

Google Scholar: Author Only Title Only Author and Title

Yuan L, Wang D, Cao L, Yu N, Liu K, Guo Y, Gan S, Chen L (2020) Regulation of Leaf Longevity by DML3-Mediated DNA

Demethylation. Mol Plant 13: 1149-1161

Google Scholar: Author Only Title Only Author and Title

Zemach A, Kim MY, Silva P, Rodrigues JA, Dotson B, Brooks MD, Zlberman D (2010) Local DNA hypomethylation activates genes in rice endosperm Proc Natl Acad Sci U S A 107: 18729-18734

Google Scholar: Author Only Title Only Author and Title

Zhang H, Lang Z, Zhu JK (2018) Dynamics and function of DNAmethylation in plants. Nat Rev Mol Cell Biol 19: 489-506

Google Scholar: Author Only Title Only Author and Title

Zhang H, Xu H, Feng M, Zhu Y (2017) Suppression of OsMADS7 in rice endosperm stabilizes amylose content under high temperature stress. Plant Biotechnol J

Google Scholar: Author Only Title Only Author and Title

Zhu JK (2009) Active DNA demethylation mediated by DNA glycosylases. Annu Rev Genet 43: 143-166

Google Scholar: Author Only Title Only Author and Title 